\section{Investigation of Steric Effects about the Amide Bond by Gas-Liquid Chromatography}

THE steric requirements of molecules dominate the rates and equilibria of many reactions in organic and inorganic chemistry. It is still difficult to make precise calculations of steric effects, but in many cases the qualitative principles controlling steric requirements have become apparent. For example, in reactions that involve addition to an unsaturated function containing a double bond, the ompirical 'rule of six' correctly states "the greater the number of atoms in the six position, the greater will be the steric effect"1. The rule of six has also been used to interpret conformations of polypeptides and proteins and to explain hydrolysis rates of di- and poly-peptides ${ }^{2}$.

We have found that the separation of diastereoisomeric pairs using gas-liquid chromatography can be used to assess steric conditions about the amide bond and that here again the rule of six correctly predicts the steric offect. In particular, we chose $\alpha$-chloro alkanoyl valine methyl esters, because they are readily prepared from the respective peptides; and we had already shown that $\alpha$-chloro alkanoyl chlorides are excellent reagents for the quantitative chromatographic resolution of diastereoisomers ${ }^{3}$. Since the presence of neighbouring polar groups may greatly modify steric factors, we have restricted our work to those compounds, derived from amino-acids, which have no hetero-atom in the side-chain. Correlation of the six-number with the ratio of retention times of the diastereoisomeric pairs is summarized in Table 1. Examination of the data suggests that the number of atoms in the 5 and 7 position is unimportant for the assessment of steric effects, but that the most hindered $\alpha$-chloro acids are those with the highest six-number. This explanation is consistent with the observation that 2-chloro-3-dimethylbutanoic acid is the best reagent for the gas-liquid chromatographic analysis of $\mathrm{D}, \mathrm{L}$-amino-acid esters.

Our results suggest that differences between the vapour pressures of the diastereoisomers are enhanced by increased crowding about the amide bond, as is shown by separations on a non-polar silicone gum rubber column $(S E-30)$ (Table 2). In addition, a more polar liquid

Table 1. CORRLiation of the RULE of Six With RAtio of RETENTION TIMES OF DIASTEREOISOMERS OF A SERIES OF N-CHLORALKANOYL VALINE

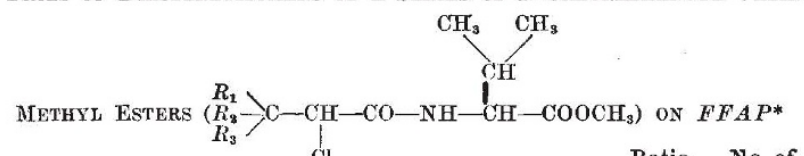

Chloro acid

2-Chloropropanoic acid

2 -Chloropropano
$R_{1}=R_{\mathbf{2}}=R_{3}=\mathrm{H}$

$R_{1}=R_{2}=R_{3}=\mathrm{H}$
2-Chlorobutanoic acid
$R_{1}=R_{9}=\mathrm{H} ; R_{3}=\mathrm{CH}$

$R_{1}=R_{2}=\mathrm{H} ; \quad R_{3}=\mathrm{CH}_{3}$
2-Chloro-4-methylpentanoic acid

$R_{1}=R_{2}=\mathrm{H} ; R_{3}=\mathrm{CH}\left(\mathrm{CH}_{\mathrm{a}}\right)_{\mathrm{s}}$

2-Chlorohexanoic acid

$R_{1}=R_{2}=\mathrm{H} ; R_{8}=\mathrm{CH}_{2} \mathrm{CH}_{2} \mathrm{CH}_{3}$
2 -Chloro-3-methylbutanoic acid

2 -Chloro-3-methylbuta
$R_{1}=\mathrm{H} ; R_{3}=R_{3}=\mathrm{CH}_{3}$

$R_{1}=\mathrm{H} ; R_{3}=R_{3}=\mathrm{CH}_{3}$
2-Chloro-3-methylpentanoic acid

$R_{1}=\mathrm{H} ; R_{\mathrm{a}}=\mathrm{CH}_{\mathrm{s}} ; R_{3}=\mathrm{CH}_{8} \mathrm{CH}_{3}$

Allo-2-chloro-3-methylpentanoic acid

$R_{1}=\mathrm{H} ; R_{2}=\mathrm{CH}_{2} \mathrm{CH}_{3} ; R_{3}=\mathrm{CH}_{3}$

2-Chloro-3-dimethylbutanoic acid

$R_{1}=R_{2}=R_{3}=\mathrm{CH}_{3}$ che carried out on a Wilkens ' $600 \mathrm{C}$ Aer was packed with 5 per cent $F F A P$ on 'C detector. The $5 \mathrm{ft} . \times 1 / 8 \mathrm{in}$. colum perature was $161^{\circ} \mathrm{C}$ and during analyses the nitrogen flow was $28 \mathrm{ml} / \mathrm{min}$.

$\dagger$ The six number for the peptide bond is obtained by adding the contribution of the valine (three atoms) to the appropriate values for the $\alpha$-chlor acid. The number system used for a peptide bond is illustrated as follows:

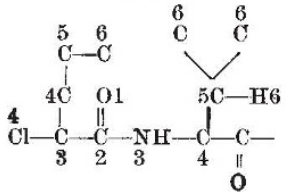

Table 2. Gas Chromatographio Separation of DIastergoisomers OF $N$-Chloratikanoya VALINE METHYL ESTERS ON SE-30*

Chloro acid

2-Chloropropanoic acid

2-Chloro-4-methylpentanoic acid

2-Chloro-3-methylbutanoic acid

2-Choro-3-methylpentanoic acid

\begin{tabular}{|c|c|c|}
\hline \multicolumn{2}{|c|}{$\begin{array}{c}\text { Retention } \\
\text { times of }\end{array}$} & $\begin{array}{l}\text { Ratio of } \\
\text { retention } \\
\text { times }\end{array}$ \\
\hline $\mathrm{I}, \mathrm{D}$ & $x, L$ & $\mathrm{~L}, \mathbf{L} / \mathrm{L}, \mathrm{D}$ \\
\hline $\begin{array}{c}5 \cdot 9 \\
17.05 \\
11.85 \\
17 \cdot 9 \\
18 \cdot 9\end{array}$ & $\begin{array}{c}6.25 \\
18.8 \\
13.5 \\
20.6 \\
21.7\end{array}$ & $\begin{array}{l}1.06 \\
1.10 \\
1.14 \\
1.15 \\
1.15\end{array}$ \\
\hline
\end{tabular}

* The $5 \mathrm{ft}$. column was packed with 5 per cent $S E-30$ on 'Chromosorb $W$ '.

The separation temperature was $140^{\circ} \mathrm{C}$ and during analyses the nitrogen flow was $28 \mathrm{ml}$. $/ \mathrm{min}$.

phase ( $F F A P$ ) improves the resolution (Table 1). We interpret the latter result as being due to secondary bonding between the amide carbonyl and the polyester column substrate. Since the magnitude of this effect will also be dependent on configuration it will be different for each diastereoisomer and further enhance the separation.

This work was supported by research grants from the National Aeronautics and Space Administration and the National Institutes of Health.

\section{Department of Genetics,}

B. HALPERN

J. W. Westley

Department of Chemistry, Stanford University, California.

${ }^{1}$ Newman, M. S., in Steric Effects in Organic Chemistru, edit. by Newman, M. S, 206 (John Wiley and Sons, Inc., New York, 1956).

${ }^{2}$ Whitfield, R. E., Science, 142, 577 (1963).

3 Halpern, B., and Westley, J. W., Chem. Commun., 246 (1965).

\section{Comparison of Diffusion of Carbon Dioxide into Hydrocarbon Systems and Polymeric Solutions}

Metzner recently reported diffusion coefficients of ethylene and carbon dioxide into polymeric and colloidal solutions ${ }^{1}$. We have measured absorption rates of carbon dioxide in mixtures of hydrocarbons of molecular weight 160-360. In this work, for a twenty-four-fold increase in viscosity the diffusion coefficients varied from $0.73 \times 10^{-5}$ to $2.50 \times 10^{-5} \mathrm{em}^{2} / \mathrm{sec}$. These data can be interpreted by existing theories on diffusion ${ }^{2}$. The values quoted by Metzner for diffusion of carbon dioxide into dilute solutions of carbopol and carboxy methyl cellulose are all within this range $\left(1.8-2.4 \times 10^{-5} \mathrm{~cm}^{2} / \mathrm{sec}\right)$ although the apparent viscosities of these solutions will be very much greater than that of the highest molecular weight hydrocarbon investigated ( 25 centipoise).

As Astarita has shown ${ }^{3}$, the values of the diffusion coefficients of earbon dioxide into polymeric solutions are very much higher than existing theories would predict. The fact that the diffusion coefficients are all of the same order as those for carbon dioxide into water and hydrocarbons suggests that, at the concentrations considered, the presence of the polymeric molecules has little effect on the molecular transport of the solute, although such molecules have a profound effect on the flow properties of the solution. At zero shear stress, the polymer molecules would not effect the diffusion of solute if they were spaced well apart in relation to the volume of the solute molecules. The increase of diffusion coefficients as the concentration of polymer molecules increases (apparent viscosity increasing) could then only be accomplished by ordering of the solvent around the polymer molecules, provided the intermolecular spacing between the polymer molecules was again very large.

A. B. Ponter

G. A. Davies

Department of Chemical Engineering, Manchester College of Science and Technology.

${ }^{1}$ Metzner, A. B., Nature, 208, 267 (1965).

Ponter, A. B., and Davies, G. A. (to be published).

${ }^{3}$ Astarita, G., Ind. Eng. Chem. (Fundamentals), 4, No. 2, 236 (1965). 